THE INDUSTRIAL INSTITUTE FOR ECONOMIC AND SOCIAL RESEARCH

WORKING PAPER No. 454, 1996 SOCIAL INSURANCE BASED ON PERSONAL SAVINGS ACCOUNTS: A possible reform strategy for overburdened welfare states?

BY STEFAN FÖLSTER 
January 18, 1996

\title{
Social insurance based on personal savings accounts: A possible reform strategy for overburdened welfare states?
}

\author{
Stefan Fölster \\ The Industrial Institute for Economic and Social Research \\ Box 5501 \\ 11485 Stockholm
}

\begin{abstract}
In spite of some cutbacks in entitlements, many welfare states' spending has continuously increased over the past decades, leading to larger tax burdens and often higher marginal tax rates. Proposals for reform often focus on reduced social insurance benefits and more actuarial insurance premia. In this paper it is shown that such reforms may have a smaller potential for reducing the marginal tax rate than commonly assumed, unless they are combined with mandatory personal savings accounts. Social insurance based on personal savings account is compared to other systems in a simple theoretical model and in a simulation within the context of Swedish social insurance. The simulation indicates that marginal tax effects can be reduced significantly by social insurance based on savings accounts without affecting life-time income distribution much.
\end{abstract}




\section{Introduction}

Many countries with extensive welfare programs have cut back entitlements during the previous decade. Yet total welfare spending has, with few exceptions tended to keep rising, a consequence in part of rising unemployment and in part of a growing share of pensioners in the population. ${ }^{1}$ Typically this expansion has been financed with higher taxes and public borrowing.

Several of the problems that afflict the welfare state appear set to pile up in coming decades. There is no indication that long-term unemployment will fall. Several countries, like Germany and Italy, face dramatic increases in the number of aged. In the meantime failure to contain spending channels a growing share of public expenditure toward servicing the public debt. As a result there is increasing pressure to raise taxes further, leading to efficiency losses that may exacerbate the growth problem.

A number of reform strategies have been proposed, often focusing on benefit cuts, and on making social insurance premia more actuarial. In practice these reform strategies often conflict with the aim or political constraint that the established minimum standard of living be maintained. As a result benefit cuts often fall disproportionately on those with medium or higher incomes, which tends to make social insurance less actuarial. Since these income groups already tend to pay more that the actuarial social insurance premium, it is difficult to make their insurance more actuarial without considerable losses of public revenue. At the same time social insurance can usually not be made more actuarial for those with smaller incomes, because higher premia would push them below the minimum acceptable standard of living.

To some extent these problems can be solved by adding a

${ }^{1}$ Between 1985 and 1992 only Germany, Belgium and Holland have cut spending on social protection while the other European welfare states have increased spending. 
mandatory personal saving account to social insurance. In most welfare states a considerable share of low income earners in any time period consist of people that have normal incomes over the course of a lifetime. A savings account into which people save when they can, and out of which they draw when they need to, provides a way to reduce subsidies to people who temporarily have low incomes, but who have higher incomes in other periods of life. At the same time insurance elements and a possibility of overdrawing the accounts in certain situations provide the economic security and the minimum acceptable standard of living for those who are low income earners throughout life.

A simple model of social insurance, provided in sections 2 and 3 , demonstrate the basic theoretical points. To assess whether introduction of personal savings account in social insurance could produce quantitively important effects a simulation of direct effects on marginal tax effects and income distribution is presented in section 4 . To assess the potential as realistically as possible, the simulation is based on the actual social insurance system in Sweden, and assumes that it is entirely replaced a savings account based social insurance. Comparisons are also made with other types of actuarial social insurance systems. The simulation is based on 1000 representative life histories.

A mandatory savings accounts as a means of financing welfare expenditures have been implemented in a few countries under various names, such as the Central Provident Fund in Singapore. As proposals for welfare state reform they have been given different names such as "personal lifetime accounts". ${ }^{2}$ Here we use the expression "savings account based social insurance" as the generic term. The expression

2 This term has been used by Eamonn Butler, head of the Adam Smith Institute (Economist, 24 June 1995, p. 24). 
"citizen account" 3 denotes the particular implementation that is analyzed in detail, and that is designed to be closely comparable to the current Swedish social insurance system.

International experience with savings account based social insurance

Most countries have some element of social insurance based on a mandatory savings account. Pension systems often work this way. A number of countries, among them Sweden, have recently reformed their pension systems, moving from an entitlement system to a contribution based system. ${ }^{4}$

Many countries also have student loan programs which can be described as savings accounts that can be overdrawn. In some countries welfare payments are given as loans in some cases. In Sweden, for example, welfare payments are repayable if the recipient finds a job within six months from receiving payment.

For other types of social insurance savings accounts are less common. One example, however, is the Chilean unemployment insurance. Newly employed are there required to save in the form of monthly installments until savings reach a value of two months' wages. If a person becomes unemployed the savings are paid back over a four month period. Only after that public assistance steps in. Saved funds

${ }^{3}$ The term citizen account is a translation of the Swedish term "Medborgarkonto" that has found acceptance in the Swedish social insurance debate.

${ }^{4}$ Under the entitlement system an estimated $75 \%$ of wage earners were in a situation where a marginal increase in pension contributions paid did not raise their expected pensions. In the contribution-based system most people will be in a situation where an increase in pension contributions actually increases expected pensions. A smaller part of contributions in the new system will be channeled into real savings accounts, while the larger part continues to work on the pay-as-you-go principle. In essence bookkeeping accounts are built up that reflect a drawing right on future generations' payments. Individuals will have some choice as to how the real savings are to be invested. This building up of real savings implies that less revenue is available to cover current pensions. To compensate for this shortfall the existing public pension funds are being drawn upon and are expected to be depleted after about 15 years. 
follow employees if they change employer. At retirement saved funds are paid out. In essence the scheme creates a larger deductible, but helps to spread the impact over a longer time period.

More comprehensive systems of mandatory savings accounts exist in Malaysia and even more so in Singapore (See Asher, 1994). ${ }^{5}$ The Singaporean Central Provident Fund was originally designed to increase savings and to provide retirement security. ${ }^{6}$ Funds in the individual accounts can be withdrawn at age 55 . Since inception the Fund has been extended with a number of schemes. These schemes provide a special account for saving for medical needs as well as a medical insurance. Among them are also schemes for financing of tertiary education, insurance of dependents and a variety of other social needs. Noteworthy is also that a number of schemes allow investment decisions for accumulated funds. Savings can be invested in own housing or in a number of approved investment funds.

${ }^{5}$ Singapore has held public transfers to households down to $0.5 \%$ of GDP compared to about $30 \%$ of GDP for Sweden. This is partly due to the Central Provident Fund, but partly due to the fact that the welfare state does not provide the same security as the e.g. the Swedish welfare state. For example there are very limited provisions for people without savings on their account.

${ }^{6}$ Gross national saving in Singapore has generally exceeded 40 percent of GDP since the early eighties. The sum of Central Provident Fund contributions and accrued interest amount to about 30 percent of gross national saving in recent years. In addition, however, the fund has helped the government to maintain a surplus, directly by being able to borrow at a low interest rate from the fund (which may be seen as a type of tax) and indirectly by keeping a lid on demands for more social spending. The government surplus accounts for a considerable share of gross national savings. 


\section{An overview}

A commonly employed method of reducing welfare states' commitments is to lower benefits in social insurance and increase fees charged for public services such as child care and health care. At the same time there is often an ambition to protect living standards of the least well-off. In combination these measures generally have ambiguous effects on marginal tax schedules, and thus incentives to work. For example, when fees for child care are raised, they are often related to income in order to protect those with low incomes. As a result poverty traps tend to deepen.

Paradoxically, increased marginal tax rates can even arise as a consequence of reduced benefits in social insurance systems where benefits are related to previous income levels. When maximum benefit levels are cut, higher incomes - and thereby higher social insurance fees - yield less in terms of expected benefits. In essence social insurance fees become less actuarial, implying a rise in the marginal tax rate.

For some types of social programs an obvious alternative to mere cutbacks is to provide an actuarial insurance that could be privately or publicly organized. ${ }^{7}$ For programs that provide income smoothing over the life cycle rather than insurance this requires some type of savings account. Actuarial income smoothing implies that the sum of an individual's payments into the system must be recorded, which is what a savings account does, and closely related to payments that the individual receives from the system.

Even in social programs that deal with insurable events, standard actuarial insurance faces a dilemma. Payment of the insurance

${ }^{7}$ Many benefits provided by the welfare state, however, contain fairly small insurance components. Parental leave compensation, for example, is more akin to a pure transfer than an insurance, since having children is not what one would consider an insurable risk. 
premium must be conditioned on declared income. This implies a clear presence of moral hazard. At least some individuals are able to withdraw from the insurance by earning less or by earning undeclared income. The presence of moral hazard implies that even an actuarial insurance gives rise to what is essentially equivalent to marginal tax effects.

Moral hazard can be addressed by introducing a deductible. The size of the deductible is limited, however, by welfare states' desire to maintain a minimum standard of living. Thus for people with a wage close to the acceptable minimum standard the deductible is effectively constrained to zero. It is shown in the simulation in section 4 that this constraint greatly limits the extent to which an actuarial insurance can reduce marginal tax effects.

A social insurance that incorporates a savings account addresses this problem by using the account to shift premium payments and deductibles to other time periods during which the individual may have greater incentives or ability to earn higher income. As a result, the savings account allows a greater average deductible than standard actuarial insurance, without compromising the minimum standard of living in any period. ${ }^{8}$ Section 3 shows these mechanisms in a simple

${ }^{8}$ One can ask why private insurance companies rarely offer common private insurance, e.g. car insurance, in the form of an account. One likely reason this does not occur more often is that insurance companies usually cannot permit a situation where customers have debts to the insurance company. A person with debts would simply switch company in order to get rid of the debt. If there is a repayment requirement even when the insurance is cancelled customers risk being locked into one insurance company. This would impede competition between companies, and is in fact illegal in many countries.

In some cases insurance companies manage to agree on a system for letting customers move between companies in spite occurrence of "debts" to the insurance company. Swedish car insurance companies have, for example, with the help of some public regulation, made it possible to move accumulated bonus between companies. Lost bonus after an accident is to a lesser extent an adjustment of premia to perceived risk levels, and to a larger extent a repayment of some of the compensation people received after an accident. Thus lost bonus can be seen as a deductible that is spread out over a number of years. This bears some resemblance to the mechanism embedded in saving 
model.

A further consideration is that a number of social insurance programs, such as parental leave, are not really insurance, but can be described as redistribution over the life cycle. In fact by one estimate 80 percent of spending on social transfers in Sweden merely smooths income over the individual's life cycle (ESO, 1994). ${ }^{9}$ This means that in a life-time perspective only 20 percent of social transfers cover two central aims of the welfare state, insurance and equalization, which both entail redistribution between individuals.

In the course of such extensive mandatory life-cycle income smoothing considerable tax wedges arise. There is rarely much of any actuarial relationship between fees and taxes on the one hand, and benefits on the other hand.

A savings account based social insurance addresses this problem by closely relating "benefits", or withdrawals, to deposits made on the account. The accounts can then be seen as a means for keeping track of an individual's payments into the system. Systems that maintain this kind of track record can in some ways also be more equitable than traditional social insurance. In traditional systems benefits are often paid in relation to current wages. This means that a person with a high wage just prior to a spell of unemployment or sickness, but a short working life can end up receiving much more accumulated benefits than a person with a low wage prior to the same

account based social insurance.

${ }^{9}$ The pension system accounts for only half of this. A significant part of social transfers that provide life cycle income smoothing are paid to individuals who have income and pay taxes simultaneous to receiving benefits. Calculations show that only $5 \%$ of GNP theoretically would need to be redistributed in order to grant everyone between the age of 20 and 64 an equal standard of living (Söderström, 1988). If one were satisfied with guaranteeing a standard of living at the level that welfare payments allow, only $0.8 \%$ of GNP would need to be redistributed (Jansson, 1990). In fact Sweden redistributes $10 \%$ of GDP to people between 20 and 64 years of age. 
spell of unemployment who happens to work more years and over the course of a life time pays much more taxes. These types of asymmetries are easily avoided in savings account based insurance.

\section{A model of social insurance}

In the beginning of each period a person knows his wage $w_{t}$ and pays a tax or an insurance premium $m_{l}$. After that he learns his actual income $y_{t}$ which may be lower than $w_{t}$ due to income losses. At the same time new information about the likelihood of future income losses is revealed. He then receives compensation $x_{t}$ for income losses and consumes $c_{i}$. Between periods the person earns interest $1+r$, and for simplicity it is assumed that the discount factor $\beta$ equals $1 /(1+r)$. The argument is not affected by different values or varying interest rates.

Expectations conditional on time $t$ information, before $y_{t}$ is revealed, is denoted $E_{t}$. Thus $E_{0} y_{0}$ refers to the expected value of $y_{0}$ in the first half of period 0 , before $y_{0}$ is revealed.

Consumers maximize a standard intertemporal utility function:

$$
\max E_{0} \sum_{t=0} \beta^{t} u(c)
$$

Assume initially that there is no moral hazard. The individual cannot avoid declaring income, reduce work effort or affect income losses.

A universal welfare state system will typically finance social 
insurance with an income-related tax, $m_{t}=\tau y_{t}$. The tax rate $\tau$ is assumed to be proportional and constant over time. In return the individual receives a compensation $x_{t}=\left(w_{t}-y_{t}\right)(1-\tau)$. Suppose that in this system the initial expected value of tax payments must balance the expected payments of compensations:

$$
E_{0} \sum_{t=0} \beta^{t} \tau y_{t}=E_{0} \sum_{t=0}^{-} \beta^{t}\left(w_{t}-y_{t}\right)(1-\tau)
$$

If $w_{t}$ were constant and the information about expected values of $y_{t}$ remained constant, this would constitute a pareto-optimal arrangement. Given a concave utility function the individual's utility is maximized with a constant consumption stream, in this case $w_{t}(1-\tau)$.

In fact, however, $w_{t}$ can vary and information on expected values changes between periods. As a result the tax an individual pays in any period will differ from the actuarial premium. In addition the consumption stream is no longer constant, and therefore no longer pareto optimal even though the state would care nothing about rearranging payments to provide a constant consumption stream.

A similar problem arises for a voluntary insurance. ${ }^{10}$ Assume that the insurer is risk neutral and competitive, and can borrow or lend at the interest rate $r$. Risk neutrality implies that individual income loss is a perfectly diversifiable risk. Competition among insurers is assumed to imply zero economic profits. Then the pareto-optimal insurance contract can easily be found under the assumption that complete contingent-claims markets exist. At time 0 the individual sells claims to his income stream and buys contingent claims to cover

${ }^{10}$ For the case of health insurance these problems are analyzed in Diamond (1992,pp. 1238-39) and Cochrane (1995). 
income losses. Then the individual's time 0 budget constraint is

$$
E_{0} \sum_{t=0} \beta^{t} c_{t}=E_{0} \sum_{t=0} \beta^{\prime} y_{t}
$$

Maximizing utility (1) subject to this constraint yields firstorder conditions that specify a constant consumption level $\mathrm{c}$ at every date and in every state. Solving the budget constraint with constant consumption gives

$$
c=r \beta E_{0} \sum_{t-0}^{-0} \beta^{\prime} y_{f}
$$

The time 0 contingent claim contract is, however, not time consistent. As soon as new information on expected values of future $y_{t}$ is revealed insurers will try to get rid of individuals with deteriorating prospects. This effect could possibly be avoided with the help of regulation. What is worse is what happens if the individual's prospects improve. The individual will then cancel the insurance, making it impossible for the insurer to cross-subsidize those with income losses. Thus, a voluntary social insurance requires lifetime ties in order to work. Such lifetime ties to private insurers are probably in conflict with legal principles in most current welfare states.

Cochrane (1995) suggests a mechanism for the related case of health insurance that could solve the problem of time inconsistency. The essence of the approach is to adjust the insurance premium in every period to reflect changed information on expected income losses, and at the same time require side payments each period that reflect the present value of changes in expectations of income losses. Thus an individual whose prospects deteriorate would receive a payment from the insurance company equalling the net present value of increases in 
future income losses. Vice versa the individual would have to make a payment to the insurance company if prospects improve.

In order to enforce the contract in a situation where individuals can go bankrupt Cochrane's mechanism requires a savings account in which savings at any time equal the possible payment that a client may have to make to the insurance company. Thus the time inconsistency problem can potentially be solved with the help of a savings account.

An obvious way around the time inconsistency problem in both Cochrane's mechanism and the universal welfare state arrangement is to introduce a mandatory, public, actuarial insurance. The insurance premia would then be set as implied by (3) and (4), while the time consistency problem is suppressed since it is impossible to switch insurance company.

So far, however, the analysis misses the essence of the welfare state dilemma. Social insurance, whether privately or publicly arranged, remains susceptible to moral hazard. In fact, the presence of moral hazard is the main motivation for attempting to keep marginal tax effects low in social insurance.

Assume that an individual can influence his income stream in a way that the state or insurer cannot detect. Let the new income stream $y_{t}{ }^{\prime}$ be the result of the individual's utility maximization.. Let the utility function be $u\left(c_{t}^{\prime}, y_{t}-y_{t}^{\prime}\right)$ such that for a constant consumption level a voluntary income loss is preferred, for example because it allows more leisure. This implies that $y_{t}{ }^{\prime}<y_{t}$. Further, if $x_{t}{ }^{\prime}$ compensates for the entire income loss s.t. $x_{t}{ }^{\prime}=\left(w_{t}-y_{t}{ }^{\prime}\right)(1-\tau)$, then the individual's utility maximization implies $y_{t}{ }^{\prime}\left(x_{t}{ }^{\prime}\right)=y_{t}{ }^{\prime}\left(\left(w_{t}-\right.\right.$ $\left.\left.y_{t}{ }^{\prime}\right)(1-\tau)\right)=0$.

In order to avoid this a deductible must be introduced. We assume that the deductible is determined by a rule $D$ that assigns a particular $D_{t}$ in every time period, conditional on variables such as $w_{t}$, $y_{t}{ }^{\prime}$ and other variables, but not on $y_{t}$ which is assumed to be unknown 
to the state or insurer. The compensation paid is then $x_{t}^{\prime}=\left(w_{t}-y_{t}^{\prime}\right)(1$ $-\tau)-D_{\imath}$.

Assume a public, mandatory, actuarial insurance that, apart from the deductible, allows a constant consumption stream. Going through the same steps that led up to (4), the individual's consumption in any period with moral hazard and a deductible becomes

$$
c_{t}^{\prime}=-D_{t}+r \beta E_{0} \sum_{t=0}^{-} \beta^{\prime}\left(y_{t}^{\prime}+D_{t}\right) .
$$

Since $y_{t}{ }^{\prime}$ is decreasing in $D_{t}$ a lower deductible lowers the individual's consumption stream. Since the insurer or the state still makes zero profit and is therefore indifferent to the size of the deductible, the socially optimal design of the system can be found by maximizing the individual's utility w.r.t. the rule $\mathrm{D}$ that determines the size of the deductible in each period.

In doing so there is an important constraint. In each period the individual must have a minimum to live on, call it MIN. This limits the size of the deductible. The maximization problem is then as in (6), where $y^{\prime}$ as defined above is the individual's optimal choice of declared income.

$$
\begin{gathered}
\max E_{0} \sum_{t 0}^{*} \beta^{t} u\left(c_{t}^{\prime} y_{t}-y_{t}^{\prime}\right) \\
\text { s.t. } D_{t} \leq\left(y_{t}^{\prime}(1-\tau)-M I N\right) /\left(w-y_{t}\right)(1-\tau) .
\end{gathered}
$$

Since the condition must be met for any $\mathrm{y}_{\mathrm{t}}{ }^{\prime \prime}$ it is clear that it is quite restrictive.

The constraint can be made less restrictive, however, by introducing a savings account. We assume a very simple version of 
the savings account based social insurance, similar to the Chilean unemployment insurance discussed further below. Assume that a deposit is made on the saving account in any period in which income $y_{i}{ }^{\prime}$ exceeds MIN and the balance on the account is below some maximum amount. The balance on the account is, in a sense, the individual's money, and the individual earns interest. In every period an annuity based on the balance in the account is returned to the individual. ${ }^{11}$ Yet the individual's expected value of making the mandatory deposits on the account is of course smaller than the actual deposits since expected future withdrawals must be taken into account.

The size of the deposit on the account in any period is $A_{1}$ and the maximum amount is governed by a rule $A$ which we do not need to specify to make the point.

Similarly withdrawals from the account are governed by a rule $\mathrm{V}$ that determines a withdrawal $\mathrm{V}_{\mathrm{t}}$ in any period. The withdrawal is zero if either the balance on the account is zero or if the constraint in (5) is met. In this case the insurance takes over. Otherwise the withdrawal $V_{t}$ is positive. Since this means that the deductible can be completely or partly paid with a withdrawal this means that the new restriction for the maximization problem (6) becomes

$$
D_{t} \leq\left(y_{t}^{\prime}(1-\tau)-M I N+V\right) /\left(w_{t}-y_{t}^{\prime}\right)(1-\tau) \text {. }
$$

Clearly this constraint is less restrictive, which means that the deductible can be made larger due to the account than would otherwise

${ }^{11}$ In a model with a finite working life the balance on the account would be returned as well at retirement. 
be possible.

The model does not say much about the size of the effect. Intuitively it is obvious, however, that this depends on the probability distributions of $w_{t}$ and $y^{\prime}{ }_{t}$. If the world divides into individuals that never have an income loss $\left(y^{\prime}{ }_{t}=w_{t}\right)$ and individuals that have a complete income loss in every period, then the account will make little difference. Those with persistent income losses, persistently have $V_{t}$ $=0$ so that (7) is identical to the restriction in (6).

If, instead, the typical pattern is that all individuals have some periods with income loss and some periods without it is clear that $V_{t}$ may be high for all individuals, and the savings account may make a big difference. In fact, this case may be more typical of a welfare state like the Swedish one, which is evidenced by the high share of social expenditure directed toward income smoothing as discussed above.

The potential for reducing marginal tax effects with the help of savings account based social insurance is investigated further in the following simulation. 


\section{The Citizen Account: A simulation}

In order to cast light on the consequences of a savings account based social insurance for marginal tax effects and income distribution a simulation is performed. In the simulation life histories are constructed for 1000 individuals, based on available empirical studies. An important aspect is that the simulation analyzes a comprehensive reform of the entire social insurance system. This is important since social insurance programs often interact in ways that make it misleading to look only at the effect of reforms on one program at a time.

A limitation is that the simulations only show the direct effects of the choice of social insurance system on marginal tax effects and income distribution. In reality these direct effects then yield indirect effects on e.g. labor supply and take up rates in the social insurance programs which in turn influence the marginal tax rates and income distribution. These indirect effects are not calculated here. Since empirical estimates of individuals' adjustment to changing marginal tax rates vary widely any assumptions about the size of these effects would be quite ad hoc. Instead, our simulation of direct effects lends itself to the interpretation that a change of social insurance system that, for a given income distribution, induces the largest direct reduction of marginal tax rates, also induces the most favorable indirect effects.

The simulation is described in four steps. First, the construction of the life cycles is explained. Then the implementation of the citizen account and the actuarial insurance are described. Finally, simulation results are shown. 
The simulation follows the basic principles in life cycle simulation models such as the Australian HARDING model (Harding, 1990) or the British LIFEMOD model (Falkingham et al., 1993). One difference is however that family history, which typically is the most complicated part in a life cycle simulation, has been considerably simplified here. Since Swedish tax and benefit rules with few exceptions are geared toward the individual with no regard to marital status we have for the most part ignored marital status. ${ }^{12}$ Thus individuals in the life cycle model are not "matched" to each other to create families. Each individual has children with a certain probability and bears half the costs of child care and other costs borne by parents.

The calculation is based on a simulated population of 1000 persons. Life cycles for the 1000 persons are constructed. It is also assumed that all incomes and prices remain as in 1990 in real terms. Life cycles begin at age 20 and end at death.

There are four steps in the construction of the simulated population:

1. Distributions of length of life, Sex, timing and length of education, and timing and number of children born to an individual are assumed to be independent of each other. Each simulated individual is randomly assigned a value of each of these variables. ${ }^{13}$

2. Income history over the life cycle is derived on the basis of empirical studies of life income streams as a function of education and $\operatorname{sex}^{14}$

3. We assume that spells of sickness are equally likely for all

${ }^{12}$ An exception is welfare payments that are conditional on the spouses income. This is implicitly handled in the simulation by using a probability of being eligible for welfare given that the individual is out of work and does not have unemployment insurance.

${ }^{13}$ The distribution of these variables are provided by the SwedishCentral Office of Statistics for 1990 .

${ }^{14}$ We have primarily relied on Björklund (1993) and Gustafsson (1994). 
categories at all stages in life, but that the duration of spells varies according to a probability table which depends on sex, age, income, and the share of previous 5 years during which the individual has been either sick or unemployed. ${ }^{15}$ Spells of sickness beyond three years of length are assumed to imply early retirement. Individuals that retire early do not work at all until they reach the age of 65 when all individuals enter normal retirement.

4. Unemployment spells are randomly assigned based on probability tables where the length of the spell depends on age, income, sex and the share of previous 5 years during which the individual has been either sick or unemployed. ${ }^{16}$

A weakness of such simulation models is that they do not capture all cross-effects well. For example, no account is taken of how education may affect sickness or the probability of having children. As one measure of robustness, however, a study using an alternative technique - creating life cycles by splicing together panel data yielded similar distribution of life time income, unemployment and sickness (ESO, Ds 1994:135).

Using the simulated income pattern and the simulated work history, payments into the social insurance in the form of payroll taxes and income taxes are calculated. Then income before and after transfers is derived. ${ }^{17}$ Based on these data it is then easy to ascertain amounts transferred between individuals on a life-time basis.

${ }^{15}$ The probability tables are provided by the Swedish Health Insurance Authority for the year 1990.

${ }^{16}$ Data underlying the probability table are provided by the Sedish Labor Market Board.

${ }^{17}$ Transfers are calculated in a simplified manner. Additional negotiated compensations are ignored. 


\section{The citizen account}

The exact tax and social insurance rules applied in the simulation are shown in the appendix. Here we provide an overview of the citizen account, and in a subsequent section, of a simple actuarial social insurance.

There are many ways to implement the concept of a savings account based social insurance. In order to study the effects of such a system more closely we concentrate here on a version denoted the "citizen account", a name that has become known in the Swedish public debate. The intention is to design a savings account based social insurance that provides the same income distribution and economic security as the current Swedish social insurance system, but significantly lower marginal tax effects.

Two versions of the citizen account are studied. In the extensive version about two thirds of current public spending would be replaced by financing through the citizen account system. Of this about 80 percent would flow via individual accounts and the remaining 20 percent are insurance premia that cover insurance elements described below.

Payments into the citizen account are mandatory and would be collected much as taxes are today. For comparability it is also assumed that the sum of mandatory payments into the account and taxes in the Citizen Account system equal taxes paid in the current system for each individual. Since we assume constant real prices and wages, the real interest rate earned on savings in the Citizen Account is assumed to be low, only 2 percent. The simulation does not endogenize dynamic effects that could occur through changes in incentives to work or changes in the saving rate. For that reason the simulation is not affected by whether the citizen account is organized as a pay-as-you-go system or a reserve system.

Payments out of the account are regulated and vary with the 
cause of income loss, previous income and other factors, just as benefit levels are in the current system. Administratively the system would therefore have many features in common with the current system. Alternatively, administration of citizen accounts could be moved to private insurance companies of clients' choosing. In either case everybody participates in the same mandatory system, thus preventing stigmatization.

The citizen account as constructed here incorporates two insurance elements. The choice of insurance principle here is largely motivated by two considerations: A) a desire be consistent with the theoretical reasoning above which implies that income is most efficiently insured over an entire life cycle, and B) to design insurance protection that is roughly similar to that achieved in the current system.

\section{Life-income insurance}

The balance that has accumulated on the citizen account at the time of retirement is converted into an annuity, thus determining the individual's pension rights. At that time claims against the life-income insurance are also calculated. Instead of insuring loss of wage income for a day or a week as the current system does, life-income insurance insures against a combination of low lifetime income and high lifetime withdrawals from the citizen's account.

Just like in most social insurance systems this implies that a person who has saved little on his citizen account, because he chose not to work at all throughout his life, will receive the lowest guaranteed pension, roughly equal to the minimum standard of living acceptable in a society. In contrast a person who has wanted to work, but has not able to due to unemployment or disease, receives a higher guaranteed pension.

In order to keep track of peoples' guaranteed pensions over the 
course of a lifetime a daily guaranteed amount (DGA) is accrued. The sum of daily amounts at retirement then determines the guaranteed pension. The DGA must be calibrated so that most people save more on their citizen account than the guaranteed level. This bears some resemblance to private pension plans that guarantee a minimal pension even if the return on invested savings develops poorly.

The desired level of redistribution between people is achieved primarily by the way the daily guaranteed amounts (DGA) are determined. The DGAs could be equal for all, independent of current income. Since the aim here, however, is to achieve a likeness with the current system, the DGAs would vary with current income and with work status. For example, actually working would imply a higher DGA than being on sick leave or being unemployed, but both of these imply a higher DGA than a person would get who chooses not to work even though he could.

The crucial difference between the life-income insurance principle and the current system is that the life-income insurance never has to step in for people who are unemployed or sick some period but who then return to work and eventually save more on their account than the guaranteed levels.

\section{Liquidity insurance}

The Citizen Account guarantees liquidity in the sense that withdrawals from the account can be made even when the balance is zero or negative. Withdrawals are regulated and administered much like in most other social insurance systems. Mimicking the current Swedish system implies that withdrawals from the account can be made with up to $80 \%$ of lost income due to sick leave or unemployment.

In addition a limit to the debt that can be accumulated on the 
citizen account is assumed, for the same reason that bancruptcy laws allow write-offs of debt. Too large a debt burden makes it improbable that the individual can ever repay the debt, and thus decreases incentives to achieve gainful employment. When the debt limit is reached, payments out of the account to the individual are offset by payments into the account by the insurance. Essentially the insurance covers withdrawals beyond the debt limit.

We analyze two implementations of the citizen account, one narrow and one wide. Table 2 shows the range of benefit programs encompassed by the two versions. Public expenditure on various transfers are shown in gross terms (ignoring for the moment that they often are taxed and therefore partially recouped by the government). In the narrow version public expenditure amounting to $9.25 \%$ of GDP would be channelled via the Citizen Account system, although a fraction of that would pay for insurance premia rather than being deposited in individual accounts. In the wide version public expenditure amounting to $41.8 \%$ of GDP would be channelled via the Citizen Account system. These figures should be compared to a total tax revenue of $48 \%$ of GDP and total public expenditure of $68 \%$ of GDP in 1994.

In the narrow version neither the pension system nor provisions for the elderly are subsumed under the citizen account system. Rather it is assumed that savings on the account are converted into an annuity at the age of 65 and added on to pensions allowed by the current pension system. ${ }^{18}$

In the wide version it is assumed that the pension system is subsumed under the citizen account system (thus working pretty much

${ }^{18}$ However a fixed sum equal to the average annuity is subtracted from pensions in order to keep the sum of annuities and pensions in aggregate equal to the sum of pensions paid under the current system. 
as it will anyway after the move towards a contribution based pension system is implemented). Again, savings on the account are converted into an annuity which constitutes the pension.

In the wide version it is assumed that most social insurance and transfers to households are replaced completely by the citizen account. In public services, however, payments are only partially made via the account. In health care, for example, it is assumed that fees are charged for common health services, amounting in sum to about 50 percent of total health care costs. These fees are financed via the account. The remaining $50 \%$ are assumed to remain publicly financed, covering high cost operations as well as a number of minor functions such as health research or disease control. In essence this provides an additional insurance against the risk of very costly health care needs. ${ }^{19}$ A number of studies suggest that this type of cost-sharing could raise efficiency in health care (e.g. Jönsson, 1995).

Schooling in the wide version is assumed to be financed via the account by tuition covering half of total costs. The remainder is publicly financed which can be justified by the fact that schooling presumably has positive external effects.

${ }^{19}$ It is assumed that health care costs including costs of medicines are financed individually up to a sum of 15000 kronor per year via the citizen account. Costs beyond that are paid publicly. For retired people the deductible is financed out of pensions provided this does not push them below the minimum pension level. This would imply that about 50 percent of health care and drug costs are financed via the account. 
Table 2. Benefits and public services encompassed by narrow and wide definitions of the Citizen Account

\begin{tabular}{llc}
\hline Benefit & $\begin{array}{l}\text { Program's } \\
\text { cost in terms of } \\
\% \text { of 1994 GDP }\end{array}$ & $\begin{array}{c}\text { Share assumed } \\
\text { financed via } \\
\text { citizen account }\end{array}$ \\
\hline
\end{tabular}

Narrow:

Unemployment benefit ${ }^{2}$

\section{7}

100

Parental leave

1.5

100

Sick benefit

1.3

100

Child benefit

1.2

100

Welfare

0.93

100

Housing benefits

0.62

100

Narrow total

9.25

100

Wide:

Pensions ${ }^{3,4}$

Housing subsidies

Student loans ${ }^{5}$

0.7

100

Education for unemployed

1.0

100

Miscellaneous transfers ${ }^{6}$

Health care

Child care

Schooling

Miscellaneous subsidies

and services ${ }^{7}$

Wide total (adjusted by share financed via the C.A.)

1 Not counting public costs of insuring the citizen account.

${ }^{2}$ Includes benefits for training during unemployment (AMU).

${ }^{3}$ Includes housing benefits to the elderly.

${ }^{4}$ Includes early retirement and work injury.

${ }^{5}$ Net of repayments.

${ }^{6}$ Includes e.g. transfers to divorced parents.

7 Includes subsidies to sport and entertainment, energy, food, renovation of houses, employment, medicine and services related to these subsidies. 
For comparability allowed withdrawals from the citizen account are assumed to equal benefits in the current system. For a number of social insurance programs this implies that allowed withdrawals would equal 80 percent of current wage up to a ceiling of 22000 .- Swedish Kronor per month (roughly 3000 US dollars). Trivially, this implies that the sum of taxes, other public income and public deficit under the current system equals the sum of payments into the citizen accounts, taxes, other public income and budget deficit under the citizen account system.

We assume initially that early retirement remains as in the current system. In the event of early retirement public insurance pays 70 percent of current wages. From this deposits are made on the citizen account as though income were regular wage. The balance on the account then determines old age pension as for all other people.

Since this is a rather generous system, and the life-income insurance provision in the citizen account offers a natural alternative organization of retirement insurance we also investigate another, less generous, possibility. In this version in the event of early retirement withdrawals are allowed from the account at a rate determined by the accumulated DGAs in the life income insurance. This would imply that young early retirees receive lower benefits than older early retirees.

Further, it is assumed that all withdrawals from the citizen account related to care of children must be made in equal proportions from both parents' accounts. This effectively prevents families from trying to abuse the life-income insurance by placing the entire burden on one parent's account.

Finally, two important redistributionary flows in the current system are retained in the citizen account system. One is that there is a redistribution from men to women who would otherwise receive 
lower pensions since they tend to live longer. ${ }^{20}$ The other is that there is a transfer from people who do not have children to people who have children. ${ }^{21}$

Given this specification of the citizen account rules it must then be insured that the rules fulfill the budget constraint. This is done by calibrating three variables in the insurance schemes so that the sum of payments into the citizen accounts and insurance premia equal total withdrawals from the accounts. The three variables are A) the minimum account balance below which liquidity insurance steps in, B) the DGA in the life income insurance and C) the guaranteed minimum pension. The calibration is described further in the appendix.

\section{Actuarial insurance without savings account}

As a benchmark we also perform simulations for a simple actuarial insurance without a savings account. The term "actuarial" insurance may be somewhat misleading. As shown in the theoretical model a savings account based insurance may in the end be more actuarial than a conventional actuarial insurance in the presence of liquidity constraints.

An actuarial insurance scheme could be implemented in many different ways, depending on assumptions about the information that the insurer can use about each individual's actuarial risk. Here we use a very simple, and perhaps unjust, specification. It is assumed that the

${ }^{20}$ Female life expectancy is used to calculate the pension annuity. This means that men are undercompensated. The surplus that arises helps to finance the insurance premia required by the system.

${ }^{21}$ For individuals with one or no children a sum is deducted from the citizen account at retirement before calculating the annuity. The sum equals 3.5 percent of life earnings net of taxes for those with no children and half that for those with one child. 
premium paid by each individual in any year exactly equals the expected value of compensation payments during the same year for people with the same age, sex, current income, and length of education. ${ }^{22}$ A constraint is implied however. If the actuarial premium charged is so large that the individual's disposable income falls below the the level of welfare payments, i.e. the minimum acceptable living standard, then a lower premium is charged, leaving the individual with the minimum living standard. ${ }^{23}$ In effect, the insurance is subsidized for low income earners, and the subsidy is withdrawn as income rises.

Compensation payments paid by the actuarial insurance are assumed to equal those in the current system. The actuarial insurance is applied to the same social programs as the narrow version of the citizen account, thus avoiding the issue of how to deal with the pension system, health care and schooling under an actuarial insurance.

A real actuarial insurance would presumably also insure against year to year changes in risk in ways that we have not taken account of here. It remains unclear how that affects the result.

\section{Simulation results}

Marginal tax rates are calculated in the simulation by letting each simulated person earn 100 kronor more during one year at a time.

${ }^{22}$ The expected value is known from the probability tables used in constructing the population, as described above.

${ }^{23}$ The excess costs that arise to the insurance due to this constraint are financed out of tax revenue. It turns out that about 60 percent of payments made by the insurance must be tax financed. 
Then the relation between the increase in payments into social insurance can be related to the discounted (by 2 percent annually) increase or decrease in the benefits received from social insurance. This quotient is defined as the marginal tax rate and is shown in tables below.

Table 4 shows what happens when the current system is replaced by a citizen account system. Results are shown for three versions of the citizen account: The narrow version, the wide version, and the wide version with a less generous early retirement provision as described above.

The marginal tax rate is calculated as explained above. It includes marginal effects in the current system of progressively increasing fees for public services and decreasing subsidies. The marginal tax rate is first shown as an average for all people and then for different income groups. ${ }^{24}$

Income is here defined in two ways. First, deciles for distribution of life time income (after taxes and subsidies) are shown. In the current system marginal tax rates are highest for high income earners, due to progressive taxation, and low income earners due to progressively reduced subsidies.

With the various versions of the citizen account marginal tax rates are much lower and more equal for all deciles except the first decile. The reason is that people in the first decile at retirement tend to have less in their account than the minimum guaranteed amount. As a result they still have some incentive to earn income as this raises the guaranteed pension, but the incentive is naturally much lower than for

${ }^{24}$ Importantly, the marginal tax calculations are based on an ex-post reasoning. Exante people will of course not know how incomes and withdrawals develop over their life time, so that the actually perceived marginal tax rate will be based on expectations of future developments. 
someone who ends up with more than the guaranteed amount on the account.

Table 4 indicates that our implementation of the actuarial insurance does not have equally large effects on the marginal tax rate as the narrow version of the citizen account. The main reason seems to be that the constraint stating that individuals' minimum living standard should be preserved has a large effect. The groups with the lowest income in any particular year tend also to have high risks of income loss during that year even though they may have low risks and high incomes in other life periods. This implies that their insurance must be subsidized. Since increasing incomes for these groups imply a reduced subsidy, the marginal effects are very high. 
Table 4 Marginal tax rates in a simulation of social insurance reform.

\begin{tabular}{lllll}
\hline Current & Narrow & Wide & Wide C.A. & Narrow \\
system & Citizen & Citizen & with less & Actuarial \\
& Account & Account & generous & Insurance \\
& & & $\begin{array}{l}\text { early } \\
\text { retirement }\end{array}$ & \\
& & & &
\end{tabular}

Marginal tax rate ${ }^{1}$ in percent

Average for all

74

54

37

33

65

Average for deciles in terms of life time income

$\begin{array}{cccccc}\text { 10th decile } & 80 & 51 & 35 & 32 & 59 \\ \text { 5th decile } & 67 & 53 & 36 & 32 & 64 \\ \text { 2nd decile } & 75 & 57 & 44 & 39 & 68 \\ \text { 1st decile } & 94 & 85 & 79 & 73 & 89\end{array}$

Average for deciles in terms monthly income

$\begin{array}{cccccc}\text { 10th decile } & 79 & 50 & 35 & 32 & 50 \\ \text { 5th decile } & 68 & 53 & 36 & 32 & 59 \\ \text { 2nd decile } & 73 & 56 & 44 & 39 & 75 \\ \text { 1st decile } & 91 & 61 & 51 & 49 & 95\end{array}$

${ }^{1}$ Includes marginal effects of benefits.

Since the aim of the Citizen Account is to decrease marginal taxes without affecting income distribution much we show income distributions for the current system and the 
versions of the Citizen Account system in table 5. Income distribution is shown as gini coefficients for life time income and for annual income, where the annual income includes benefits or withdrawals from the account in order to ensure comparability with the current system.

Table 5. Life income distribution

$\begin{array}{lllcc}\text { Current } & \text { Narrow } & \text { Wide } & \text { Wide C.A. } & \text { Narrow } \\ \text { system } & \text { Citizen } & \text { Citizen } & \text { with less } & \text { Actuarial } \\ & \text { Account } & \text { Account } & \text { generous } & \text { Insurance } \\ & & \text { early } & & \\ & & \text { retirement } & & \end{array}$

Gini life income

(per year)

0.119

0.118

0.121

0.122

0.24

Gini annual income

0.281

0.281

0.283

0.284

0.37

Clearly overall income distribution is not much affected by a switch to the citizen account. This is no surprise for annual income since withdrawals allowed from the account were designed to match current benefits. It is more remarkable, however, that the distribution of life time income remains virtually unaffected by a switch to the citizen account. This corroborates evidence discussed above that only a small fraction of current welfare spending actually is redistributed from high-income to low-income individuals.

These results on overall income distribution do not preclude existence of redistributionary effects between groups of people that do not perturb the overall distribution. This is a question that should perhaps be studied further. We have, however, not been able to discern any 
obvious such effects. In the appendix a life history for a low income person is presented which to some extent illustrates why even low-income people fare relatively well under the citizen account system.

The actuarial insurance induces a significant shift in the income distribution. It should be rembered however that this is based on a particular implementation of actuarial insurance that probably does not cover changes in risk levels well. In particular it appears that risks and expected compensations are quite high during age 20-35, when many peoples' incomes are low. The high actuarial premia essentially push a large fraction of this age group to the minimum standard of living.

\section{Conclusion}

Willingness to consider new solutions is increasing in the face of growing problems that most welfare states experience. The solution offered by saving account based social insurance could potentially be politically attractive because it combines lower marginal tax rates with the demands for economic security and redistribution between individuals that many insist on. On the other hand a change of system like that envisioned here would pose formidable demands of politicians pedagogical abilities. A realistic development would therefore probably occur piecemeal - like in Chile - with separate accounts initially being created for different types of social insurance. Eventually these accounts can then be merged.

An important question is what technical difficulties a conversion would face. Clearly, saving account based social insurance, just like any other social insurance system, cannot quickly be transformed from a payas-you-go system to a reserve system. As explained above, however, saving account based social insurance can easily function as a pay-as-yougo-system and, if desired, a slowly increasing share can be covered by 
real reserves that individuals may have some freedom to invest as they wish.

A saving account based social insurance could be introduced for a younger cohorts only, thus leading to a gradual transition. It would be quite possible, however, to organize a simultaneous transition for all. This would require that for each type of person an account balance is imputed, depending on age, sex, accumulated tax payments and perhaps a few other variables. A mixture of these approaches is actually being used in Sweden's current pension reform. 


\section{References}

Asher, M. G., Social security in Malaysia and Singapore - practices, issues and directions, Institute of Strategic and International Studies, Malaysia, 1994.

Andersson, Åke, E, 1994. Humankapitalets framtida finansiering. Ds 1994:30, Utbildningskonton. Rapport nr 11 till Agenda 2000.

Björklund, A. A comparison between actual distribution of annual and lifetime income: Sweden 1951-1989, The Review of Income and Wealth, 39:4, 377-386.

Cochrane, J.H. Time -consistent health insurance. Journal of Political Economy, 1995, vol. 103, 445-475.

Edwards, S., Why are saving rates so different across countries?: An international comparative analysis, NBER Working Paper no. 5097, 1995.

ESO, Ds 1994:135. Skatter och socialförsäkringar över livscykeln - en simuleringsmodell. Ministry of Finance, Stockholm.

Falkingham, J. \& Lessof, C., Playing God: Constructing a dynamic Cohort Microsimulation Model. Welfare State Programme, London School of Economics, 1993.

Fölster, Stefan, Barkman, Catharina, Meyerson, Eva \& Pyddoke, Roger, 1993, Sveriges systemskifte $i$ fara - erfarenheter av privatisering, avreglering och decentralisering. Industriens Utredningsinstitut. Stockholm.

Fölster, Stefan, 1994a. Kompetenskonto - ett förslag till finansiering av livslångt lärande. Ds 1994:30, Utbildningskonton. Rapport $\mathrm{nr} 11$ till Agenda 2000.

Fölster, Stefan, 1994b, Socialförsäkring genom medborgarkonto: Vilka är argumenten? Ekonomisk Debatt, 22, nr.4., 387-397.

Harding, A., Lifetime income and redistribution in Australia: Applications of a dynamic cohort microsimulation model, London School of Economics, 1990.

Jansson, Kjell, 1990. Inkomst- och förmögenhetsfördelningen 1967-1987, 
Långtidsutredningen 1990, bilaga.

Jönsson, B., Cost sharing for pharmaceuticals: The Swedish reimbursement system, Sharing the costs of health: A multi-country perspective, Pharmaceutical Partners for Better Healthcare, Basel: Switzerland, July 1995.

Snower, Dennis. J., 1993. The future of the welfare state, CEPR Occasional Paper no.13.

Söderström, Lars., 1988. Inkomstfördelning och fördelningspolitik, SNS, Stockholm. 


\section{Appendix}

This appendix describes the tax and social insurance rules applied in the current system, the Citizen Account system and the actuarial insurance.

Current system:

Tax schedule: From gross income (before employer's tax) the following taxes are drawn:

Employer's tax $35 \%$

Income tax $31 \%$ of net income (after employer's tax) and additional $25 \%$ for income over 191000 .Swedish krona per year.

Value added tax $14 \%$ on remaining income after employer's and income taxes. VAT rate is $19.2 \%$ for most goods and services, but lower for some.

Bargained or voluntary insurance provided by the employer is ignored.

Social Insurance benefits:

Unemployment benefit $\quad 80 \%$ of previous net income up to 168 000 .- per annum. In practice not limited in time.

Parental leave

$80 \%$ of previous net income up to 231 000.- per annum, paid for one year.

Sick benefit

$80 \%$ of previous net income up to 231 000 .- per annum. No compensation first day, $65 \%$ second day.

Child benefit

750 kronor per month and child.

Welfare

6500 .- per month for grown-up, 2500 ,. per child.

Housing benefits vary locally, here we assume the average figure of 1100.- kronor per month for individuals with income of 6 500.-, after that reduced with 50 kronor for each increase of income by 100 .-.

Pensions

$65 \%$ of previous net income during 15 years with highest 
income. Minimum pension for

those without previous income 7 500.-

kronor per month which includes

supplementary housing benefit.

Student loans During higher education 5000.- per month.

Education for unemployed Spread evenly over unemployed, 1500.- per month.

Miscellaneous transfers Spread evenly over all, 450.- kronor per month.

Health care

Own average cost for fees is 60 kronor per sick day. Average system costs for health care is 694.- per sick day.

Child care

System costs are 61000 .- per year and child. Parents pay 23 000.- per year and child.

Schooling

System costs are 24000 .- per year and child, own costs are zero.

Citizen Account:

Rules for allowed withdrawals from the Citizen Account are equivalent to rules for size of benefits in the current social insurance as stated above. Deposits on the Citizen account are calculated as equivalent to taxes paid as described below, minus premia for the life income and liquidity insurances. Since many of benefits in the current system are paid out of general tax revenue it is necessary to allocate taxes to the programs that are included in the narrow and wide versions of the Citizen Account. This has been done as follows. The programs in the narrow version are assumed to be financed by the entire employers tax excepting pension contributions plus 24 percent of direct tax revenue. The programs in the wide version are assumed to be financed by the entire employers tax plus 74 percent of direct and indirect taxes.

The insurance premia and the life income insurance benefits are determined by a process of calibration. Calibrating the Citizen Account system is mainly a question of adjusting the insurance schemes so that the sum of payments into the Citizen Accounts and insurance premia equal total withdrawals from the accounts. 
The exact variables we can adjust are the minimum level on the account MIN, and the size of the daily pension guarantee (DGA) which we express as a linear function of the average wage earned over a person's working life (age 18-64). In the current system the minimum pension after taxes and subsidies is 60 percent of the net average wage, here denoted as MINPENSION. The guaranteed pension in the Citizen Account system is then:

MINPENSION + DGA * Individual's average wage over life

In table 3 some combinations of MINPENSION and DGA are shown at which payments into the Citizen Account system equal payments out of the system. For both the narrow and the wide version values of MINPENSION and DGA converge in the middle column. This is convenient, and is therefore chosen for the simulations reported below.

Also, table 3 shows the share of the payments into the system that are paid as insurance premia, with the remainder being paid into individual accounts. The insurance premia, which are collected proportional to deposits, shown in table 3 are around 18 percent. Thus 82 percent of incoming payments are deposited on the individual accounts.

The insurance premium is not entirely equivalent to a tax since it does have an actuarial element. Higher income, leading to higher deposits on the account and higher insurance premia also imply higher guaranteed pension. ${ }^{25}$

${ }^{25}$ On the other hand there is a hidden tax due to the redistribution between men and women, and childless and parents mentioned above. 
Table 3. Distribution of guaranteed pensions under different assumptions.
(1)
(2)
(3)

Narrow version:

MIN

(in Swedish kronor) $-220000 \quad-280000 \quad-350000$

DGA
0.15
0.18
0.21

Wide version:*

MIN

(in Swedish kronor) $-200000 \quad-283000 \quad-350000$

$\begin{array}{llll}\text { DGA } & 0.15 & 0.18 & 0.21\end{array}$

* version with generous early retirement provision.

Assuming the values in the middle column of table 3,14 percent of all people end up with less on their account at retirement age than what is guaranteed by the life income insurance. As it turns out even people with prolonged periods of absence and withdrawals for parental leave and child care costs can end up with a pension above the guaranteed amount.

To illustrate this we show a typical life history of a low income person in diagram $1 .{ }^{26}$ Here the wide version of the Citizen Account is assumed. The diagram shows wage income, guaranteed pension and the pension the individual actually achieves due to saving on the account.

${ }^{26}$ The individual is assumed to work full time between the age of 18 and 24 , while having one child at the age of 22. After that he/she becomes unemployed and begins an education followed by a second child. At the age of 31 the individual starts working half time. At the age of 41 this increases to 3/4 time and at the age of $46 \mathrm{he} / \mathrm{she}$ begins working fulltime. During a long period the balance on the account is negative, but by the age of 57 the balance actually exceeds the guaranteed amount, allowing a pension higher than the guaranteed pension. 


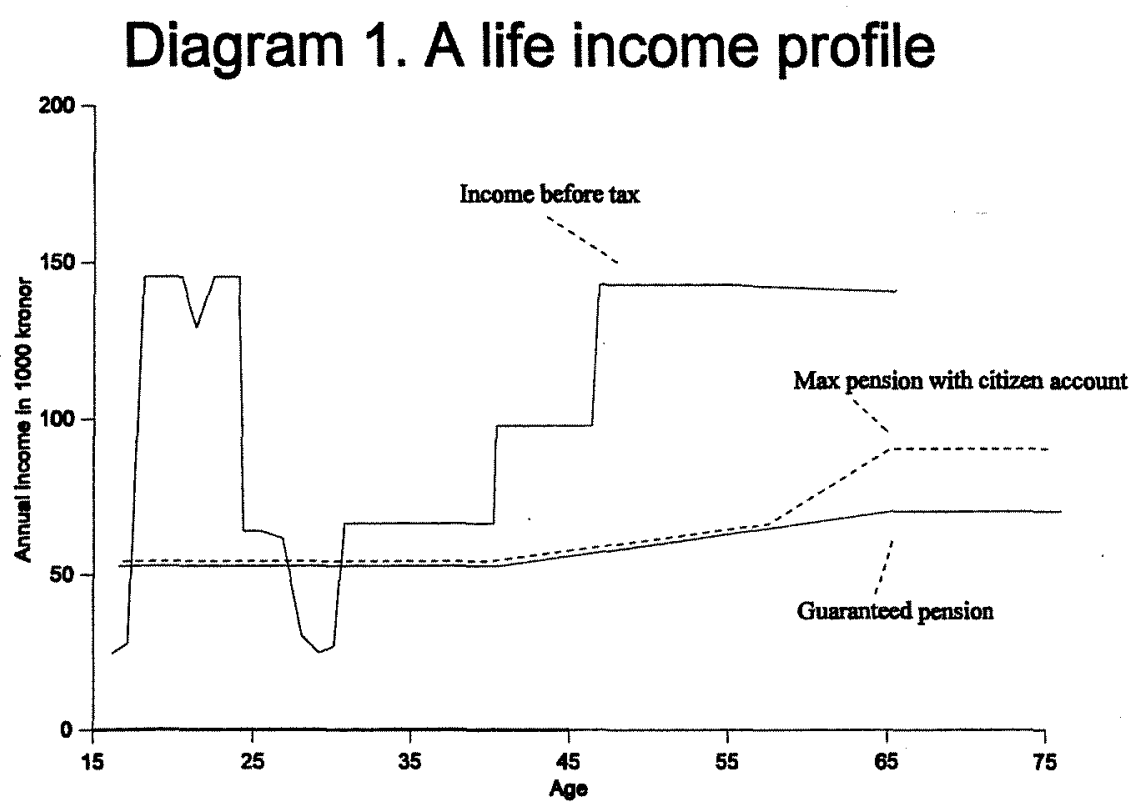

